Caught between sympathy and suspicion: : Journalistic pÿperceptions and practices of telling asylum seekers personal stories

\title{
Pantti, Mervi Katriina
}

2019-11

Pantti , M K \& Ojala , M M 2019 , ' Caught between sympathy and suspicion: Journalistic pÿperceptions and practices of telling asylum seekers personal stories ' , Media, Culture \& Society , vol. 41 , no. 8 , pp. 1031-1047 . https://doi.org/10.1177/0163443718756177

http://hdl.handle.net/10138/306201

https://doi.org/10.1177/0163443718756177

acceptedVersion

Downloaded from Helda, University of Helsinki institutional repository.

This is an electronic reprint of the original article.

This reprint may differ from the original in pagination and typographic detail.

Please cite the original version. 
This is a post-peer-review, pre-copyedit version of an article published in Media,

Culture \& Society. The final authenticated version is available online at:

http://dx.doi.org/10.1177/0163443718756177. 


\title{
Caught between sympathy and suspicion: journalistic perceptions and practices of telling asylum seekers' personal stories
}

\begin{abstract}
Personal stories in news reports serve multiple purposes, but at their core lie efforts at illustrating and authenticating a social or political issue through human experience, an illustration that is compelling in its affective appeal. Telling the personal stories of people belonging to minority groups may work as a potent journalistic vehicle in countering negative stereotypes and prejudices against them. This article examines how Finnish journalists incorporate the personal stories of asylum seekers into their coverage of the so-called 'European refugee crisis' of 2015-2016. Drawing on qualitative interviews, we inquire into how journalists understand the meaning and purpose of asylum seekers' personal stories in their news reporting and reflect on the professional values and ethical dilemmas when telling them. Our findings reveal that while journalists tend to sympathise with the vulnerable and see it as important to combat xenophobia and racism, their relationship with asylum seekers becomes increasingly informed and constrained by socio-political and discursive structures that foster a culture of suspicion towards asylum seekers.
\end{abstract}

Keywords: asylum seeker, journalism, personal story, suspicion, ethics 


\section{Introduction}

Ali's face is timid and solemn. The 18-year-old Iraqi youth has been given the final negative verdict on his asylum application. The police have given him 30 days to pack his bags and leave the reception centre in Vantaa. The police exhort Ali to return to Iraq. 'I cannot go back', Ali says. 'I would be killed - I know that.' His eyes are filled with fear and confusion.

Ali says that his father, who worked as a truck driver, was kidnapped and killed for having in his possession video material about the illegal activities of government forces. After his father had been killed, the forces began to threaten Ali. That was when he decided to flee to Europe. Ali's mother and six younger siblings also fled their hometown of Basra. Now they live in exile somewhere in Iraq. Ali does not know where. (Katri Merikallio, Suomen Kuvalehti, 16 December 2016.)

Personal asylum stories such as Ali's, published in the above-mentioned Finnish current affairs magazine, tell readers about experiences of displacement, persecution, broken families, fear and hope. Personal stories are commonly incorporated into the news to render social and political issues more tangible and encourage audiences to identify and empathise with the affected individuals or groups through the narration of their lived 
experiences (Kunelius and Renvall, 2010; Wahl-Jorgensen, 2013). As such, they have been identified as a critical tool for journalism in addressing social or political processes and challenging the dominant rhetoric and public policy (Birks, 2016; Macdonald, 2000). For members of a marginalised group struggling to have their voices heard in society - in this case, refugees and asylum seekers - personal stories provide one channel for expressing their grievances and claiming recognition.

Asylum is an immensely contentious political issue, which can be perceived in the responses that combine suspicion and empathy in both political discourse and the media. While hospitality has been the proclaimed policy of Western European countries, hostility firmly coexists with hospitality in national asylum processes and policies (McFadyen, 2016). The existing literature on news representations of asylum seekers is predominantly negative, demonstrating the construction of asylum seekers as threats. This literature rightly assumes that news representations contribute to marginalisation and dehumanisation, for instance by normalising a hierarchy of asylum labels that separate genuine asylum seekers from bogus and illegal types (Moore, 2013). Negative constructions of asylum seeking as an economic choice or as an abuse of the Western welfare system absolves host countries from responsibility and legitimises antiasylum seeker policies by, as Every and Augoustinos (2008: 648) state, presenting tougher immigration law 'as the only logical solution to the arrival of asylum seekers'. 
However, parallel to this predominantly dehumanising narrative runs a counter humanising narrative, one that has received less critical attention. We address this gap in the existing literature by focusing on how news and current affairs journalists made use of the personal stories of asylum seekers during the European refugee crisis of 2015-2016. We also contribute to the existing research by moving beyond representations of asylum seekers and examining personal narratives from the previously overlooked perspective of journalists' perceptions and practices. Clearly, the dehumanising narrative emerging from textual analyses sits uneasily with the ethical frameworks of journalists, particularly with the ideals of pursuing social justice and giving voice to the disadvantaged. Hence, we approach personal stories in the news as counter-narratives to the profusion of negative rhetoric about asylum seekers in public discourse. Yet, we argue that journalists' attempts to challenge the negative media and government rhetoric about asylum seekers by giving them a human face and voice are circumscribed by a pervasive 'culture of disbelief', in which the narratives of asylum seekers and their advocates are viewed with suspicion (Bohmer and Shuman, 2007; Every and Augoustinos, 2008). In other words, these humanising stories in the news are inevitably contingent upon the existing discourses about asylum seekers, oscillating as they do between suspicion and empathy, as well as upon the contexts in which they are told. 
Our article is devoted to the ways in which journalists themselves make sense of personal stories in the midst of public anxieties, racism and oppressive policy changes. Using interviews with Finnish journalists working in print and broadcast media, we examine the emotional investments, professional ideals, ethical tensions and sociopolitical constraints underpinning the use of asylum seekers' personal stories in journalistic reporting. Examining journalists' perceptions of asylum reporting is important because the way in which journalists understand their role and responsibility shapes the news we see and hear, and consequently, our perceptions of social reality.

In 2015, the number of asylum seekers in the member states of the European Union (EU) doubled compared with 2014. Surveys show that popular opinion turned increasingly negative towards immigration in practically all EU countries around this time (Eurobarometer, 2016). In Finland, 32,476 people applied for asylum in 2015, a nearly tenfold increase in the number of applications received in the previous year. The extent of anti-immigrant mobilisation, including acts of violence against refugee centres and a torrent of hate speech against liberal politicians, activists and journalists, was unprecedented. In early 2016, the centre-right coalition government, which includes the anti-immigration nationalist-populist Finns party, implemented a series of amendments to the Aliens Act, with the explicit aim of making Finland a 'less attractive' destination for refugees. While the number of new asylum seekers in Finland decreased after 2015, 
asylum policy has remained a highly contested and incendiary topic in the national debate.

\section{Asylum seekers' stories in a culture of suspicion}

Various intermediaries bear witness to the stories that refugees and asylum seekers tell about the causes and repercussions of their migration (e.g. Givoni, 2014; Woolley, 2017). Narratives of individual struggles, together with close-up photographs of migrant faces, constitute what Tyler (2006: 194-195) calls 'close-up technologies' that aim to humanise refugees and asylum seekers. Such affective technologies, adopted primarily by humanitarian organisations, are believed to effectively stimulate empathy towards strangers. Indeed, personal narratives lie at the heart of various actors' (including journalists') attempts to raise public concern for the plight and human rights of asylum seekers (e.g., Ihlen et al., 2015).

Personal stories in the news contain asylum seekers' accounts of their past persecution and suffering as well as the injustices they experienced in the host country, thereby offering a route to asylum seekers to speak for themselves. However, asylum seekers' testimonies must meet specific challenges of credibility as a form of evidence, which also shapes the ways in which journalists construct personal narratives in their 
reporting. These challenges are related to the broader problem of credibility with respect to treating asylum seekers' testimonies of persecution as central sources of evidence to support their claims for protection. To be recognised as refugees, asylum seekers need to convincingly present themselves as being deserving of protection (e.g. Eastmond, 2007; Woolley, 2017). However, asylum seekers' testimonies are constantly being scrutinised for their authenticity, and they are increasingly being discredited both within national asylum processes and by the hosting publics (Fassin, 2013; Shuman and Bohmer, 2004; Smith, 2017). As Fassin (2013) argues, the general increase of asylum seekers over the last decades has been accompanied by a profound suspicion of them in both national administrations and public discourse (see also Kyriakides, 2017). As a consequence, immigration policies have become increasingly restrictive and the proportion of applicants obtaining a refugee status has declined. In the present conjuncture, this suspicion has undoubtedly reached a new peak.

The sharing of asylum seekers' stories on digital networks has arguably contributed to a culture of suspicion. As Givoni (2016: 4) argues, testimonial narratives have become indispensable to a wide variety of political projects in the contemporary media environment. However, Internet forums and social media have provided new contexts not only for representing migrants in terms of human rights and suffering, but also for suspicious and hateful readings of asylum seekers' testimonies and the news coverage that is sympathetic towards them. 
News reporting contributes to this culture of suspicion by reproducing representations of and discourses about asylum seekers that are typically structured around the themes of illegality and dishonesty (Bennett et al., 2013; Gale, 2004; Tyler, 2006). To date, a wide array of studies have examined how a mistrust of asylum seekers is constructed in the news and how such mistrust works to hinder asylum seekers' social inclusion via a number of linguistic and visual strategies (Bleiker et al., 2013; El Refaie, 2001). Other studies have focused on how news coverage helps perpetuate existing stereotypes of asylum seekers as criminals, economic migrants and abusers of the social welfare system (see Harrison, 2016; Holmes and Castañeda, 2016). Similarly, recent studies indicate that asylum seekers have mostly been presented in the European media as posing a security risk and causing cultural or economic problems, with far fewer stories giving asylum seekers a voice to articulate their own viewpoints (Berry et al., 2016; Georgiou and Zaborowski, 2016). Despite the often negative portrayal of asylum seekers, media coverage continues to be crucial to both asylum seekers and the advocate groups supporting their cause, as it provides them with a channel to air their grievances and build a broader base of solidarity for promoting their cause (see Ihlen and Thorbjørnsrud, 2014).

In emphasising the role of the mainstream media in dehumanising asylum seekers, scholars typically disregard the representational practices that in fact give a voice to asylum seekers and delineate their common humanity. This is not to deny that the 
mainstream media, or some forms of it, position asylum seekers as invaders, frauds and threats, but rather to assert that it is crucial to critically examine those particular media frames and formats that include asylum seekers' experiences and points of view in the public discourse (see Cottle, 2006; Figenschou and Thorbjørnsrud, 2015; Moore, 2015). On the other hand, there are national differences in the extent to which asylum seekers and refugees voices are represented in the mainstream news coverage of immigration. Thorbjørnsrud and Figenschou (2016) show that while administrative and political elites are the dominant source in all national media studied, Norwegian news media is more accommodating to the immigrants' points of view.

Undoubtedly, journalists sometimes position themselves as advocates, speaking on behalf of asylum seekers and representing them sympathetically through personalised stories permeated by ideas regarding humanitarianism and human rights (Gale, 2004; Hallin, 2015; Robins, 2003). Professional ideals, such as exposing injustices and abuses of power and promoting equality and change to improve the conditions of the socially disadvantaged, inform news reporting that treats asylum seekers as fellow humans deserving of recognition and a voice in public discourse (Benson, 2013; Ettema and Glasser, 1998; Kyriakides, 2017).

\section{Journalism and personal stories}


This article focuses on personal stories in the news that cover the experiences and emotions of asylum seekers in depth. The role of such stories - variously called exemplars, cases or personal stories - in facilitating engagement with social and political issues has received considerable attention in research on media effects. Studies focusing on exemplification or personalisation regularly point out that emotional personal stories elicit a higher level of interest from audiences and affect their biased understanding and attitudes about the issue being reported (Aust and Zillmann, 1996; Bas and Grabe, 2015; Brosius and Bathelt, 1994; Grabe et al., 2017). Grabe et al. (2017) find that a reporting style that includes emotional testimonies from ordinary people affected by an issue can enhance empathy for and identification with those people.

Telling personal stories has been a contested narrative strategy in journalism. Not only does the representation of ordinary people's experiences destabilise the elite and expert-driven logic of sourcing the news (e.g., Reich, 2015), in using personal stories, journalists also balance between objective and more emotionally evocative styles of reporting. Eliciting emotional responses by presenting individual narratives has, unsurprisingly, been perceived by many in the industry as inferior to dispassionate hard news reporting and belonging to the market-driven media. The human-interest story has been criticised for producing ill-informed citizens by simplifying the debate, that is, of obfuscating the structural causes and reducing the range of viewpoints being offered 
(e.g. Bas and Grabe, 2015; Benson, 2013). A counter argument is that the use of personal stories can increase the public's understanding of important issues if journalists are able to connect the personal experiences to broader social and political issues (Birks, 2016; Macdonald, 2000).

Nonetheless, the personalisation of news is by no means limited to popular or tabloid media. In fact, Hallin (2015) argues that it is simplistic to connect humaninterest stories to market logic. They can be characteristic of the most highly regarded forms of journalism, such as investigative reports that attempt to raise moral outrage through personal testimonies (Ettema and Glasser, 1998; Wahl-Jorgensen, 2013). In the democratic corporatist media systems of the Nordic countries (including Finland), which entail a high level of professionalisation and a strong public service ethos, journalists are also expected to report the perspectives of marginalised members of society (Hallin, 2015). Thus, journalists' use of personal stories can be driven by moral goals, such as unsettling dominant perceptions about refugees and highlighting broader social injustices by providing detailed insights into the experiences of specific asylum seekers (Macdonald, 2000). In this sense, a personal story is an ethical device employed by journalists to counter the marginalising and dehumanising discourses in the public realm (see Craig, 2003). 


\section{The study's data and methods}

The data consisted of semi-structured interviews with 24 Finnish journalists working in national, regional and local news media. At the national level, the media included three nationwide newspapers, the public service broadcaster, the largest commercial TV channel and the most popular current affairs magazine. At the regional level, the media comprised seven regional newspapers and two regional newsrooms of the public service broadcaster. Additionally, two municipal newspapers were selected due to certain refugee-related events in those localities, which had received national interest.

The interviewed journalists included those persons with the most extensive experience in reporting on asylum seekers and related issues for their respective newsrooms since the summer of 2015. The interviews were conducted between December 2016 and February 2017, each lasting approximately 90 minutes. The general themes were as follows: (1) the aims and professional ideals of refugee reporting; (2) the quality of refugee reporting in the newsroom and national media; (3) personal experiences in interviewing asylum seekers and reporting on the issue; and (4) feedback from audiences and the general opinion regarding asylum seekers.

Methodologically, we approached the interviews as evaluations of the journalists' own actions and experiences vis-à-vis their professional community and the news media 
in general. According to Zelizer (1993), journalists can be regarded as forming an interpretive community whose members are connected by shared discursive practices when making sense of social reality and of themselves as actors. This notion draws attention to how journalists construct a 'shared reality' with their colleagues through 'the social validation of judgments' (Donsbach, 2008: 66-68), enabling them to gain confidence in their ability to work professionally. Accordingly, we paid specific attention to how the journalists made sense of their actions and experiences in terms of a shared professional discourse, alluding to ideas, beliefs, values and principles that they assumed to be collectively held by their colleagues. Indeed, when asked about their personal motives in asylum reporting, the interviewees often referred to journalists or the media in general, thus blurring the line between personal values and collective norms. We focused in particular on repeated arguments and accounts and interpreted them as indications of the broader professional discourse about how to incorporate asylum seekers' personal stories into news coverage.

The Finnish media system is characterised by a strong level of professionalism that relies on objective reporting, watchdog functions and journalistic autonomy (Ahva et al., 2017). The political press is marginal, and most of the mainstream media outlets target the broadest possible audience. Analysis of current issues, interpretation (as opposed to the dissemination of facts) and participation in public debate are generally valued by Finnish journalists; however, Finnish journalists tend to detach themselves 
from political parties and interests, voicing clear-cut stances only on matters related to democratic principles, human rights and self-evident injustices (Reunanen and Koljonen, 2016). We expected that our interviewees would have aligned themselves with these basic ideals and norms of Finnish journalists, with personal stories serving their purposes of analysing and interpreting developments in the 'refugee crisis' as well as enhancing the societal debate on asylum.

\section{Analysis}

\section{Motivations and sensitivities behind using personal stories}

For journalists covering the unprecedented increase in the number of asylum seekers, personal stories provided a human-interest angle to this complex and unfamiliar phenomenon. In our interviews, the journalists described personal stories - the need and rationale for them - in terms that were connected to three traditional normative frameworks of journalism: the search for the truth, the watchdog ideal and the deliberative democracy function. When the desire to support the cause of asylum seekers emerged in the interviews as a motivational factor behind asylum reporting, it was articulated within these broader ethical principles. 
First, the central journalistic principle of seeking the truth informed the choice of incorporating asylum seekers' personal stories into the reporting. The refugee crisis was approached as an important news event, one in which the journalists' duty was to provide a detailed and full picture to the greatest extent possible. Bringing the truth of the 'refugee crisis' to the public included the idea that the truth would not be complete without providing a diversity of viewpoints (see Murphy et al., 2006). Asylum seekers' stories thus contributed to journalistic knowledge production as one relevant viewpoint among many, including those of asylum officials, local authorities, aid organisations and local people. One interviewee articulated the role of journalists as public educators in the following way:

I strongly feel that our task as journalists is to provide information for readers and open windows that help the readers see [the world] from a perspective that is an alternative to their everyday surroundings. Everyone is surrounded by the social media uproar all the time, but people don't get these kinds of [investigative] stories from social media. These are facts. These are real things. These are real-life stories. These are real people who come here, and in my opinion, reporters should bring them to the readers. (Journalist 1, current affairs magazine)

By telling the personal stories of asylum seekers, the journalists believed that they were increasing public understanding of the asylum seekers' situations and their diverse 
backgrounds, thus bridging the emotional distance between 'them' and 'us'. The idea of seeking out the truth through asylum seekers' stories was often intertwined with the journalists' belief that addressing the gaps in knowledge would also lead to empathy and identification. Truth seeking was thus entwined with the journalists' broader goals, such as fostering solidarity. This moral goal was stressed in the journalists' professed hopes of proving that asylum seekers were 'just like us', with similar needs, hopes and dreams. Such re-categorising of asylum seekers as 'just like us' has been identified as one of the key strategies for mobilising empathy and countering anti-asylum rhetoric (Every and Augoustinos, 2008; Kyriakides, 2017). Indeed, as many Finns began volunteering to help asylum seekers, part of the credit was directed at the media for having given the refugees a human face.

Second, the journalists made sense of their use of personal stories within the classical-liberal framework of watchdog journalism - traditionally endorsed by Nordic journalists (Ahva et al., 2017) - wherein journalists ensure institutions' accountability by scrutinising those in positions of power. The other side of the watchdog function is to give voice to the people, particularly vulnerable groups. Here, stories of asylum seekers' pain served to reveal failures in the asylum system as well as human rights violations. As the Finnish government responded to the refugee situation by adopting repressive policies, personal stories illustrated their human outcomes. 
Some of the interviewed journalists explicitly identified themselves as advocates for those who were in a vulnerable position in society and acknowledged that they sought out stories of abused asylum seekers to intervene in the public debate. Their goal was to highlight cases of negligence or incompetence by asylum officials or injustices in the asylum process in order to trigger public outrage and put pressure on officials.

We should find more ways to challenge, for instance, the government $[\ldots]$. Everyone knows that the Finnish asylum policy is restrictive, so what would be the case that would blow the lid off? That would take uncovering a powerful story again, something that people could identify with. That's just how it goes. It is very hard in this climate to find anything that would fly. It would require having some riveting new information, or it should be some really horrific personal story. (Journalist 2, public service media)

Actively furthering the asylum seekers' cause was nevertheless a controversial position among many journalists. Some explicitly stated that it was neither their intention, nor should it be the purpose of journalists in general, to become public advocates for asylum seekers. For them, personal stories merely served their detached watchdog efforts at monitoring the system and the conduct of officials. 
The third prevalent framework was deliberative democracy, to which journalism contributed by giving voice to various actors and enhancing the quality of the debate. This point became apparent when the journalists alluded to the climate of public opinion, which they believed had become both increasingly polarised and hostile towards asylum seekers. Many of the journalists expressed concern that the public discussion had turned not only increasingly racist and xenophobic but also overtly aggressive, threatening the free expression of opinions. Their professional duty was to defend the principles of liberal democracy against the attacks of radical right-wing groups and to counter these groups' nationalist and xenophobic propaganda. The personal stories served an important role in the journalists' task of destabilising the culture of suspicion:

I was really shocked by the amount of racism here and shocked about how some people reacted. This made me want to tell the truth about those issues, and not just something that the $M V$ [a radical-right news site] and Hommaforum [an online discussion forum notorious for its anti-immigrant agenda] spread. Because of so much disinformation, I wanted to tell [the readers] that these [asylum seekers] are just ordinary people. (Journalist 3, regional newspaper)

The preceding quote illustrates how many journalists perceived of themselves as being involved in the struggle against anti-immigrant online sources regarding the 
prevailing public perceptions of asylum seekers. In this struggle, sharing personal stories was intended not only to counter unfounded fears, myths and prejudices, but also to improve the quality of public debate by enabling both the opponents and defenders of asylum seekers to engage in more fact-based argumentation. Indeed, the journalists frequently reasoned that they could help cut through the disinformation circulating on social media by bringing asylum seekers to the fore and telling their real-life stories.

Professional and ethical challenges in constructing a personal story

Writing the personal stories of asylum seekers in a highly politicised atmosphere presented various ethical tensions and practical dilemmas for journalists. The main challenges in constructing personal stories were (1) limited time and access to sources, (2) dealing with the often questionable authenticity of asylum seekers' stories and (3) the constant balancing act required between the choice of using personal narratives to achieve audience engagement and the demands for objectivity and non-partisanship based on both professional norms and interested publics.

First, constructing personal stories is a resource-intensive form of journalism. One reason that refugees lack a voice may be that telling the stories of their lives would require news organisations to make a relatively high investment in resources (see 
Figenschou and Thorbjørnsrud, 2015; Hallin, 2015). Besides the general time constraints when working on stories, the journalists often referred to various practical restrictions affecting their access to relevant sources. For instance, the lack of relevant language skills and the limited availability of interpreters created significant obstacles to conducting interviews, especially in local and regional news media. Hence, journalists could not easily provide a viewpoint that was embedded in the realities of the asylum seekers. Language problems made the interviews highly time-consuming experiences because the journalists had to go over the same issues several times to ensure that all the details had been correctly understood.

A second set of challenges in constructing personal stories had to do with how to adequately judge their authenticity and veracity. Practically all the journalists cited problems arising from the impossibility of verifying their interviewees' stories. When conducting interviews with asylum seekers, the journalists constantly assessed the credibility of what they were being told and developed practices to distinguish between genuine stories and fake stories. The journalists asked their interviewees not only to provide official documentation and evidence to support the stories, but also to repeat their stories in detail many times. While checking the accuracy of the information given by sources is a typical feature of journalism and its effort to ensure trustworthiness, the asylum seekers seemingly represented a special case for the journalists. Several journalists pointed out that they seldom suspected other non-official sources, at least not 
to the extent that they questioned asylum seekers' testimonies. The journalists gradually learned to approach asylum seekers with informed suspicion. As one journalist reflected, she had effectively turned into an interrogator.

After interviewing so many of these asylum seekers, you develop quite an eye. So if the same story is told for the fifth time, you start to think 'no way'. I mean, you can already see who is telling the truth and who isn't. And the more I get details from the interviews, the more I know that there is something to it [the story]: because she can describe it so vividly. I do these kinds of personal asylum interviews with people, like the Finnish Immigration Service does, too, asking the same questions. And sometimes I ask myself, 'Wait a minute, what is the job that I am doing?' (Journalist 4, national newspaper)

Encountering discrepancies and gaps in the asylum seekers' stories, coupled with the inability to fully verify them, often presented great difficulties in judging what to include in a story and how much credibility to give to the facts. This situation often entailed ethical considerations about whether to exercise restraint in telling the whole truth when writing the story: should journalists tell readers about suspected lies or embellishments - which might be damaging to asylum seekers as a group? One journalist shared her experience in working on a feature story about a refugee family. 
Having followed the family's life for a year, during which time their story had changed several times, she found herself facing a difficult internal conflict.

I sometimes notice that they lie to me, and it is confusing. I am not sure what to do and how to make it known if I notice that I am being lied to, even though I cannot really prove that either. But I don't have a reason [for not telling the story], even though I am more like a tolerant person [i.e. not anti-immigration]. So it is a balancing act of sorts. I am working on a big story that has some obvious factual contradictions, and I haven't yet worked out how to solve them. (Journalist 5, regional newspaper)

To make a story appealing and encourage empathy towards asylum seekers, journalists might feel tempted to refrain from providing conflicting information that would present the asylum seeker in an unfavourable or suspicious light. Treating asylum seekers as vulnerable victims also meant that the journalists did not always probe deeper into their stories for accuracy or the underlying motives as thoroughly as they believed they should have. On the other hand, the journalists also emphasised their obligation to include potentially incoherent and confusing elements so as not to compromise the principle of truth telling (see Murphy et al., 2006: 325). Overall, the self-criticism of their use and presentation of personal stories indicated that journalists had to constantly balance between their advocacy role and the professional principles of objectivity and critical detachment from their sources. 
It is a funny thing that every time one talks about the suffering of an interviewee, a temptation arises to highlight that suffering and to sort of go deeper into the mind of that person. But somehow, one has to always remember to use expressions like 'Ahmed says' or 'Ahmed claims' or 'Ahmed says he was tortured by the police', and so on, that you cannot put words into the journalist's or newspaper's mouth. (Journalist 6, national newspaper)

Third, the interviews made it evident that the important values of advancing the perspective of asylum seekers, fostering solidarity and defending vulnerable individuals against the injustices of the asylum system constantly clashed with how journalists experienced the expectations and pressures imposed on them by the broader social and political contexts. Asylum reporting in Europe takes place in a highly inflammatory context of public debate, one in which nationalist-populist parties and radical right-wing groups have been successful in claiming to represent the people. These same groups aggressively promote the view that adopting the refugee's perspective and defending an asylum seeker against the structural violence of the state are unpatriotic acts and against the people's interest. In such circumstances, Finnish journalists could no longer consider representing asylum seekers as neutral or apolitical acts. Many interviewees noted that whenever they wrote a story emphasising the suffering of an asylum seeker, their email and social media accounts became flooded with angry messages accusing them of attempting to manipulate public opinion in favour of the refugees. 
In my opinion, asylum seekers' experiences deserve more visibility if people want to understand better what misery at its worst could be [like]. I mean, that kind of suffering that we don't know in Finland; for instance, that you are being persecuted because of your religion. This better understanding could soften attitudes towards asylum seekers more generally. But when you write about this suffering [...], you can be sure that you will receive email comments saying, 'Why do you try to whitewash them?' [...] And all you have to do to receive them is that you humanise the subject, show that she/he is a suffering individual. (Journalist 7, national newspaper)

As the preceding quote indicates, the journalists became increasingly self-aware of public perceptions regarding asylum seekers that their coverage potentially reinforced. The journalists often felt that publishing erroneous information would backfire and incite anger on social media about biased journalists. Therefore, telling personal stories always presented a threat to journalistic credibility, a credibility that was crucial in establishing the authenticity of asylum seekers' stories.

These are often pretty complex cases, so when interviewing an asylum seeker, one should check all the stories and backgrounds and preferably with as [much] solid evidence as possible. [...] When mistakes are made in these cases, stupid factual errors, they serve to increase distrust. Because when reporters make 
mistakes in these issues, it is absolutely certain that [such] mistakes will be noticed. And then these mistakes will be spread and used as yet more evidence about how the mainstream media tries to keep things under wraps. (Journalist 8 , public service broadcaster)

Constructing personal stories thus appeared to require a balancing act between narrative appeal and journalistic credibility in the eyes of an increasingly suspicious public. To avoid accusations of bias or the wilful manipulation of audience perceptions, the journalists needed to tell the asylum seekers' stories in as neutral a fashion as possible. Moreover, the risk of presenting false information and becoming an uncritical mouthpiece for asylum seekers had to be mitigated via an increasingly meticulous investigation and questioning of their personal stories.

\section{Normalisation of suspicion}

The journalists' emphasis on the often unresolvable problems in terms of verifying the stories of their sources indicated the complex relationship between them and the asylum seekers. Our interviewees reported encountering plenty of disinformation, lies, exaggerations and attempts by asylum seekers to take advantage of journalists. One journalist recounted a situation in which an asylum seeker contacted his brother over Skype from Britain during the interview in a manner that appeared highly 
choreographed. The journalist felt that the situation had effectively turned into something resembling a press conference. According to the journalists being interviewed, asylum seekers often assumed that publicity might somehow advance their own cases in the asylum process. Several interviewees also acknowledged that asylum seekers might have strong motives for telling a 'modified truth' about their circumstances. The journalists thus learned to perceive asylum seekers not so much as idealised victims, but as interested parties, and to question their hidden motives.

Whenever they tell their story to the media, obviously there is often this hope behind it that it would somehow advance their own situation. If our interest in talking with them is to gain information, their interest is in driving their own agenda and justifying why they personally need asylum. This often means that there is plenty of exaggeration regarding the kind of personal persecution they have experienced. (Journalist 7, national newspaper)

Their experiences with asylum seekers attempting to manipulate them gave journalists further impetus to approach their subjects with suspicion. However, the journalists faced a double challenge in this instance: they had to gain their interviewees' trust while actively questioning the credibility of what they were being told. Nonetheless, one journalist thought that this double role of serving as a confidant and an interrogator was not problematic because the asylum seekers too were fully aware of 
many 'fortune seekers' making up their stories. In fact, those with 'genuine cases' fully acknowledged that it was in their own interest that reporters were trying to separate them from the 'bogus' asylum seekers.

I often try to explain [this point to] them because surely it is not an easy situation to give one's personal documents to a reporter whom one does not know. But they do understand that, especially if they have the right intentions, so to speak. They know that there are all kinds of people out there. And if they really have a genuine case, they know that this is for their own benefit. (Journalist 1, current affairs magazine)

It seems that both journalists and asylum seekers began to internalise the culture of suspicion. When faced with questioning and disbelief, asylum seekers typically accepted their obligation to produce evidence to back up their stories; in other words, they accepted their role as 'suspects'. Sometimes these efforts confounded journalists.

He [the interviewee] was an interpreter by profession and was, hence, proficient in English. But he eagerly tried to prove himself to me. It sort of felt that he was repeating a pattern that he probably had adopted when talking to officials - that he had to prove himself with pictures and whatnot, that he had a family and that they had been in contact, even though they were living in different countries. So he eagerly showed me the pictures even though I did not ask to see them. I did 
not doubt him, and the details were none of my business. What he told me about getting his family here, I had no reason to doubt. But I felt he really had had to convince people. (Journalist 9, regional newspaper)

Overall, the interviewees indicated that as they became more experienced in interviewing asylum seekers, the journalists approached them with an increasingly critical detachment. A journalist working for the public service broadcaster even commended Finnish journalists for becoming less naïve with respect to asylum seekers. To her, asylum reporting had improved and become 'more realistic after the initial euphoria'. However, the same journalist also lamented how asylum reporting repeatedly represented refugees as passive objects and disregarded their own agency. The problem in her view was how journalism could find a balance between maintaining disinterested objectivity and adopting a humane approach toward asylum seekers as persons struggling for a better life, similar to everybody else:

It's very difficult to give them some active agency, that the asylum seeker is a genuinely active subject and not simply an object. And then to reflect their individuality and humanity so that Finns could identify with them. [...] There is cold objectivity versus simultaneously being human, because it is not, after all, a crime to travel to another country to seek a better life. And it is not a crime either 
to present white lies for your personal advantage. I guess we would all at times succumb to that, and we do. (Journalist 2, public service broadcaster)

These worries highlight the journalists' difficulty in balancing an asylum seeker's position as a victim and an active agent (see Robins, 2003): asylum seekers became either innocent victims who were represented as powerless or actors in search of a better future for themselves and their families. This latter position, while seemingly legitimate and understandable, was problematic for journalists because it echoed the right-wing populist stigma of refugees as 'asylum shoppers'. Therefore, the active position threatened to delegitimise asylum seekers as abusers of the system. Here, one can detect implicit regrets about the culture of suspicion that makes all asylum seekers potential frauds, while the basic issues of humanity and the desire to make a better life for oneself are overlooked (Kyriakides, 2017).

\section{Conclusions}

By making refugees visible, personal stories in the news intervene in debates about social justice and human rights. The journalists who mediate these stories speak on behalf of asylum seekers, making them visible and countering the abundance of 
dehumanising representations (see Szörényi, 2009). As a narrative device, personal stories employ several strategies to destabilise the culture of suspicion, increase knowledge about asylum seekers' (diverse) backgrounds and struggles, stress the similarities between 'us' and asylum seekers, counter disinformation and vividly depict their suffering and persecution (Every and Augoustinos, 2008).

Journalists themselves clearly recognise the power of personal stories. In a previous study, journalists generally agreed that reporting on refugee issues could be made more balanced and truthful by raising the profile of refugee and asylum seeker voices (The Information Center about Asylum and Refugees in the UK, 2004). In a similar vein, we found that the Finnish journalists who had reported extensively on the asylum issue typically approach personal stories within ethical and moral frameworks, emphasising their ability to engender empathy and understanding. For them, personal stories appeared as soft weapons that could educate the public on how to perceive asylum seekers as individuals 'just like us'.

Nevertheless, even when asylum seekers' voices do make it into the news, their potential to engender empathy may be significantly compromised. Our study indicates that the journalistic construction of personal stories is a highly complicated exercise, imbued with problems arising from established traditions within the profession, the broader socio-political context in which refugee journalism is practised and the available refugee discourses. First, the various practical and ethical challenges brought 
up by our interviewees demonstrate both unease about journalistic practices in asylum reporting and uncertainty about the professional norms that should guide their relationship with asylum seekers. The professional norms of accuracy, objectivity and critical detachment clearly clash with the ideals behind telling the personal stories of asylum seekers in the first place, including social inclusion and defending the vulnerable.

Second, broader political and cultural factors shape the way journalists incorporate and construct the personal stories of asylum seekers in their reporting. Having become highly involved with the issue, many of our interviewees expressed strong feelings about the increasingly restrictive policy measures adopted by the government as well as the hardening climate of opinion against asylum seekers. They understood the value of personal stories as political devices, as ways to intervene in the public debate over asylum policy, the way in which the asylum system operates and the impact of refugees on the national culture and society. Yet, despite journalists' generally critical attitudes towards the influence of anti-immigrant forces in the societal debate over refugees, their relationship with asylum seekers is also shaped by these same antiimmigrant discourses. Given the power of the government, nationalist right-wing groups and the logic of the asylum system itself to determine much of the terms of the debate, the overwhelming position is one of distrust and prejudice. As a result, the 
journalists tend to become uneasy about asylum seekers as sources and increasingly wary about advocating their cause.

Our study on Finnish journalists' reflection on the use of the personal stories of asylum seekers in their reporting thus points to broader political and cultural factors at play. In the contemporary European context marked by the rise of anti-immigrant populism and an increasingly restrictive approach to immigration policy (Harrison, 2016; Khiabany, 2016), journalists and asylum seekers alike operate in of a general culture of suspicion, which treats all asylum seekers as potential frauds and criminals. In a political climate hostile to asylum seekers, their stories, as they appear in the news, are met with heightened suspicion and criticism, complicating and circumscribing journalists' notions of how they should present asylum seekers in their stories. Hence, while personal stories have the potential to cut through public cynicism and engender a feeling solidarity with the disadvantaged, journalists recounting these narratives are themselves torn between their ethical ideals and professional norms, on the one hand, and societal expectations and prejudices on the other.

\section{References}


Ahva L, van Dalen A, Hovden JF, Kolbeins GH, Nilsson ML, Skovsgaard M and Väliverronen J (2017) A welfare state of mind? Nordic journalists' conception of their role and autonomy in international context. Journalism Studies 18(5): 595613.

Aust CF and Zillmann D (1996) Effects of victim exemplification in television news on viewer perception of social issues. Journalism \& Mass Communication Quarterly 73(4): 787-803.

Bas $\mathrm{O}$ and Grabe ME (2015) Emotion-provoking personalization of news: informing citizens and closing the knowledge gap? Communication Research 42(2): 159-185.

Bennett S, ter Wal J, Lipiński A, Fabiszak M and Krzyżanowski M (2013) The representation of third-country nationals in European news discourse: journalistic perceptions and practices. Journalism Practice 7(3): 248-265.

Benson R (2013) Shaping Immigration News: A French-American Comparison. New York: Cambridge University Press.

Berry M, Garcia-Blanco I and Moore K (2015) Press coverage of the refugee and migrant crisis in the EU: a content analysis of five European countries. Available at: http://www.unhcr.org/56bb369c9.pdf (accessed 2 November, 2017). 
Birks J (2016) 'Moving life stories tell us just why politics matters': personal narratives in tabloid anti-austerity campaigns. Journalism 1-18. DOI:

$10.1177 / 1464884916671159$

Bleiker R, Campbell D, Hutchison E and Nicholson X (2013) The visual dehumanisation of refugees. Australian Journal of Political Science 48(4): 398416.

Bohmer C and Shuman A (2007) Political Asylum in the $21^{\text {st }}$ Century. London and New York: Routledge.

Brosius HB and Bathelt A (1994) The utility of exemplars in persuasive communications. Communication Research 21(1), 48-78.

Cottle S (2006) Mediatized Conflict. Maidenhead: Open University Press.

Craig DA (2003) The promise and peril of anecdotes in news coverage: an ethical analysis. Journalism \& Mass Communication Quarterly 80(4): 802-817.

Donsbach W (2008) Factors behind journalists' professional behavior. In: Löffelholz M and Weaver D (eds) Global Journalism Research. Oxford: Blackwell, pp. 65-78.

Eastmond M (2007) Stories as lived experience: narratives in forced migration research. Journal of Refugee Studies 20(2): 248-64. 
Ettema JS and Glasser TL (1998) Custodians of Conscience: Investigative Journalism and Public Virtue. Columbia University Press.

El Refaie E (2001) Metaphors we discriminate by: naturalized themes in Austrian newspaper articles about asylum seekers. Journal of Sociolinguistics 5(3): 352371.

Eurobarometer (2016) Public opinion in the European Union, National Report: Finland, Autumn. European Union.

Every D and Augoustinos M (2008) 'Taking advantage' or fleeing persecution? Opposing accounts of asylum seeking. Journal of Sociolinguistics 12(5): 648-667.

Fassin D (2013) The precarious truth of asylum. Public Culture 25(169): 39-63.

Figenschou TU and Thorbjørnsrud K (2015) Faces of an invisible population: human interest framing of irregular immigration news in the United States, France, and Norway. American Behavioral Scientist 59(7): 783-801.

Gale P (2004) The refugee crisis and fear: populist politics and media discourse. Journal of Sociology 40(4): 321-340.

Georgiou M and Zaborowski R (2016) Media coverage of the 'refugee crisis': a crossEuropean perspective. Council of Europe Report no. DG1(2017)03. London: LSE. 
Givoni M (2016) The Care of the Witness: A Contemporary History of Testimony in Crises. New York: Cambridge University Press.

Grabe ME, Kleemans M, Bas O, Myrick JG and Kim M (2017) Putting a human face on cold, hard facts: effects of personalizing social issues on perceptions of issue importance. International Journal of Communication 11: 907-929.

Hallin D (2015) The dynamics of immigration coverage in comparative perspective. American Behavioral Scientist 59(7): 876-885.

Harrison AC (2016) Mediations of 'the refugee crisis': the (ir)reconciliation of ideological contradictions in Fortress Europe. Networking Knowledge 9(4). Available at: http://ojs.meccsa.org.uk/index.php/netknow/article/view/449/271 (accessed November 9, 2017).

Holmes SM and Castañeda H (2016) Representing the 'European refugee crisis' in Germany and beyond: deservingness and difference, life and death. American Ethnologist 43(1): 12-24.

The Information Center about Asylum and Refugees in the UK (ICAR) (2004) Media Image, Community Impact: Assessing the Impact of Media and Political Images of Refugees and Asylum Seekers on Community Relations in London. London: ICAR. 
Ihlen Ø, Figenschou T and Larsen A (2015) Behind the framing scenes: challenges and opportunities for NGOs and authorities framing irregular immigration. American Behavioral Scientist 59(7): 822-838.

Ihlen $\varnothing$ and Thorbjørnsrud K (2014) Making news and influencing decisions: three threshold cases concerning forced return of immigrants. European Journal of Communication 29(2): 139-152.

Khiabany G (2016) Refugee crisis, imperialism and pitiless wars on the poor. Media, Culture \& Society 38(5): 755-762.

Kunelius R and Renvall M (2010) Stories of a public: journalism and the validity of citizens' testimonies. Journalism 11(5): 515-529.

Kyriakides C (2017) Words don't come easy: Al Jazeera's migrant-refugee distinction and the European culture of (mis)trust. Current Sociology 65(7): 933-952.

Macdonald M (2000) Rethinking personalization in current affairs journalism. In: Sparks C and Zelizer B (eds) Tabloid Tales: Global Debates over Media Standards. Oxford: Rowman \& Littlefield, pp. 251-266.

Murphy J, Ward S and Donovan A (2006) Ethical ideals in journalism: Civic uplift or telling the truth? Journal of Mass Media Ethics 21(4): 322-337. 
McFadyen G (2016) The language of labelling and the politics of hostipitality in the British asylum system. The British Journal of Politics and International Relations 18(3): 599-617.

Moore K (2013) 'Asylum shopping' in the neoliberal social imaginary. Media, Culture \& Society 35(3): $348-365$.

Moore K (2015) Editorial: The meaning of migration. JOMEC Journal 7. DOI: http://doi.org/10.18573/j.2015.10001

Reich Z (2015) Why citizens still rarely serve as news sources: Validating a tripartite model of circumstantial, logistical, and evaluative barriers. International Journal of Communication 9: 2412-2433.

Reunanen E and Koljonen K (2016) Not partisans, but participants. The quantity and quality of journalistic interventionism in Finnish journalists' professional ethos. Journalism Studies. DOI: 10.1080/1461670X.2016.1204940.

Robins MB (2003) 'Lost boys' and the promised land: US newspaper coverage of Sudanese refugees. Journalism 4(1): 29-49.

Smith K (2017) Telling stories of resistance and ruination: Women seeking asylum. Journal of Resistance Studies 2 (2): 33-64. 
Szörényi A (2009) Till human voices wake us: responding to refugee testimony. Life Writing 6(2): 173-191.

Thorbjørnsrud K and Figenschou T (2016) Do marginalized sources matter? Journalism Studies 17(3): 337-355.

Tyler I (2006) 'Welcome to Britain': the cultural politics of asylum. European Journal of Cultural Studies 9(2): 185-202.

Wahl-Jorgensen K (2013) The strategic ritual of emotionality: a case study of PulitzerPrize winning articles. Journalism 14(1): 129-145.

Woolley A (2017) Narrating the 'asylum story': between literary and legal storytelling. Interventions 19(3): 376-394.

Zelizer B (1993) Journalists as interpretive communities. Critical Studies in Mass Communication 10(3): 219-237. 